\title{
AÇÃO DE FUNGICIDAS SOBRE DOIS CULTIVARES DE FEIJOEIRO EM CAPÃO BONITO, SP ( ${ }^{1}$ )
}

\author{
JAIRO LOPES DE CASTRO ${ }^{(2,5)}$, MARGARIDA FUMIKO ITO ${ }^{(3)}$, \\ CHRISTINA DUDIENAS ${ }^{(3)}$, EDUARDO ANTONIO BULISANI $(4,6)$ \\ - LUIZ D'ARTAGNAN DE ALMEIDA $(4,5)$
}

\begin{abstract}
RESUMO
Avaliou-se, no controle de doenças do feijoeiro, ovs. Carioca e Carioca 80, a eficiência de onze fungicidas, aplicados na parte aérea, isoladamente, em condiçöes naturais de infecção. Os ensaios foram efetuados em condiçб̋es de campo nas safras da seca e das águas de 1985 e 1986, na Estação Experimental de Capão Bonito, pertencentes ao IAC. Foram utilizados os seguintes tratamentos fungicidas: benomil, tiofanato metílico, captafol, clorotalonil, acetato de trifenil estanho, carbendazim, tiabendazol, oxicloreto de cobre, sulfato de cobre e hidróxido de trifenil estanho. $\mathrm{Na}$ safra da seca/85, pulverizaçסes com captafol, clorotalonil, acetato de trifenil estanho e carbendazim proporcionaram as melhores produções do 'Carioca', $\theta$ os fungicidas mancozebe, clorotalonil, acetato de trifenil estanho, oxicloreto de cobre e sulfato de cobre, as melhores produçōes do 'Carioca 80 '. Nas safras das águas/85 e da seca/86, os produtos testados não influíram estatisticamente na produção dos dois cultivares. $\mathrm{Na}$ safra das águas/86, os melhores tratamentos para o 'Carioca' foram acetato de trifenil estanho e hidróxido de trifenil estanho e, para o 'Carioca 80', apenas o hidróxido de trifenil estanho. A antracnose foi detectada apenas no 'Carioca', nas safras da seca/85 e das águas/86. Na seca/85, todos os fungicidas controlaram a doença nas folhas, sendo 0 clorotalonil $\Theta 0$ acetato de trifenil estanho os melhores para vagens. Nas águas/86, tanto em folhas como em vagens, os melhores tratamentos foram mancozebe, captafol, clorotalonil, acetato de trifenil estanho e hidroxido de trifenil estanho. Para a ferrugem, que não foi uma doença muito importante, ocorrendo apenas em duas safras, seca/86 e águas/86, com baixa incidência, o fungicida que mostrou algum controle foi o clorotalonil. Para o controle da mancha-angular, a doença de maior freqüência e severidade, e da mancha de Alternaria e bacteriose, que, com menor severidade, também ocorreram de forma generalizada em todas as safras, os tratamentos mais eficientes foram mancozebe, clorotalonil, acetato de trifenil estanho e hidróxido de trifenil estanho.
\end{abstract}

Termos de indexação: feijoeiro, Phaseolus vulgaris L., doenças, controle químico, rendimento.

(') Trabalho apresentado na II Reunião Nacional de Pesquisa de Feijão, realizada em Goiânia (GO), em 10-15 de maio de 1987. Recebido para publicação em 26 de março e aceito em 18 de setembro de 1991.

(2) Estação Experimental de Capão Bonito, Instituto Agronômico (IAC), Caixa Postal 28, 13001 Campinas (SP)

(3) Seção de Fitopatologia, IAC.

(4) Seção de Leguminosas, IAC.

(5) Com bolsa de pesquisa do CNPq.

(6) Com bolsa de doutorado da CAPES. 


\title{
ABSTRACT \\ FUNGICIDES ACTION ON TWO BEAN CULTIVARS IN CAPÃO BONITO,SÃO PAULO STATE, BRAZIL
}

\begin{abstract}
Eleven fungicides were sprayed on field crops of two beans (Phaseolus vulgaris L.), cvs. Carioca and Carioca 80 , to evaluate their effect on yield performance and disease control under natural conditions of infection. The trials were carried out during four periods: fall of 1985 and 1986 and spring of 1985 and 1986. The tested fungicides were: benomyl, mancozeb, methil thiophanate, captafol, chlorothalonil, triphenyltin acetate, carbendazim, thiabendazole, copper oxychloride, copper sulfate and triphenyltin hidroxide. During the fall of 1985 the fungicides captafol, chlorothalonil, triphenyltin acetate and carbendazim resulted in high yield for the cv. Carioca; while for the cv. Carioca 80, mancozeb, chlorothalonil, triphenyltin acetate, copper oxychloride and copper sulfate were more efficient. During the spring of 1985 and fall of 1986, the fungicides did not give a significant increase on yield. During the spring of 1986, the best fungicides for the 'Carioca' were triphenyltin acetate and triphenyltin hidroxide, and for the 'Carioca 80', the triphenyltin hidroxide was the best fungicide. The rust was not a very important disease. It occurred only in two periods: fall and spring of 1986 and the higher medium note was 2 (as $25 \%$ of the foliar area was affected). The best fungicide for the control of this disease was chlorothalonil. The leaf spot caused by Phaeolsariopsis griseola was the most frequent and severe disease. The leaf spot caused by Alternaria occurred in all periods. The leaf spot caused by Xanthomonas campestris pv. phaseoli also occurred on a generalized form, but, it did not affect the pods of the tested cultivars. These three diseases were better controled by mancozeb, chlorothalonil, triphenyltin acetate and triphenyltin hidroxide.
\end{abstract}

Index terms: beans, Phaseolus vulgaris L., yield, diseases, chemical control.

\section{INTRODUÇÃO}

O feijão é a principal fonte de proteína vegetal do povo brasileiro, seu maior consumidor mundial. É também boa fonte de calorias, vitaminas e minerais, como fósforo, potássio, cálcio e magnésio (SGARBIERI, 1987). O Brasil é o maior produtor mundial de feijão, apresentando, porém, baixa produtividade, quando comparado com outros países. O Estado de São Paulo é o primeiro produtor do País, com uma produção de $325.926 \mathrm{t}$ e uma produtividade média de $876 \mathrm{~kg} / \mathrm{ha}$ (ANUÁRIO ESTATÍSTICO DO BRASIL, 1990).

Entre os mais importantes fatores da baixa produtividade, encontram-se as doenças que, em alguns casos, constituem fator limitante da cultura. Segundo MAFFIA et al. (1988), aproximadamente 108 fungos, 24 nematóides, 19 vírus e 17 bactérias são citados como patógenos do feijoeiro. Desses, uma pequena minoria é bastante importante em condições brasileiras. Entre as doenças, destacam-se antracnose (Colletotrichum lindemuthianum), ferrugem (Uromyces phaseoli var. typica), mancha-angular (Phaeoisariopsis griseola), e crestamento comum (Xanthomonas campestris pv. phaseoli). Recentemente, a mancha de Alternaria, causada por Alternaria spp., também tem sido importante. 
Alternativas para o controle das doenças do feijoeiro são citadas na literatura, sendo o controle químico uma delas. Para o controle do crestamento comum, é indicado o oxicloreto de cobre em mistura com zinebe (KIMATI et al., 1986; MARINGONI, 1988), além de oxicloreto de cobre em mistura com mancozebe (MARINGONI, 1988).

Fungicidas à base de benomil, carbendazim, clorotalonil, mancozebe, tiabendazol e tiofanato metilico são os mais recomendados para o controle da antracnose (ROLIM et al., 1981; TANAKA \& JUNQUEIRA NETTO, 1982; ISSA et al., 1983; VIEIRA, 1983; ISSA, 1985; SARTORATO, 1985, e CASTRO et al., 1989) e, mais recentemente, o tolifluanide tem mostrado efeito (GOULART, 1989).

Segundo ZAMBOLIM \& CHAVES (1978), para o controle químico de ferrugem do feijoeiro, recomenda-se o uso de carboxim ou carboxim em mistura com oxicarboxim. Outros princípios ativos também são indicados para o controle dessa doença: tiofanato metilico (TANAKA \& JUNQUEIRA NETTO, 1982); clorotalonil, mancozebe (SARTORATO, 1985, e CASTRO et al., 1989); triforine (ROLIM et al., 1985, e SARTORATO, 1985); diniconazole (MANÇO, 1988); bitertanol (SANTINI, 1989) e etiltrianol (GOULART, 1989, e SANTINI, 1989).

TANAKA \& JUNQUEIRA NETTO (1982), ISSA et al. (1983), VIEIRA (1983), ROLIM et al. (1985) e RODRIGUES et al. (1987) observaram eficiência de benomil e tiofanato metilico no controle da mancha-angular. CASTRO et al. (1989) obtiveram controle dessa doença com o uso de clorotalonil e mancozebe. Bitertanol e etiltrianol também foram eficientes no controle da mancha-angular (GOULART, 1989). Diversos produtos mostraram-se eficientes para o controle de mancha de Alternaria: benomil (ISSA et al., 1983, e CASTRO et al., 1989); mancozebe, tiofanato metflico e clorotalonil (CASTRO et al., 1989); tolifluanide e anilazine (GOULART, 1989).

Este trabalho teve como objetivo reavaliar o efeito, em condições de campo, de onze fungicidas no controle das doenças e na produção.

\section{MATERIAL E MÉTODOS}

Na estação Experimental de Capão Bonito do IAC, em condições naturais de infecção, avaliou-se o efeito de onze fungicidas no controle das doenças do feijoeiro, dos cultivares Carioca e Carioca 80, nas safras da seca e das águas de 1985 e 1986. Nas safras da seca, os plantios foram efetuados em fevereiro e as colheitas, em maio, e nas safras das águas, os plantios foram efetuados em setembro e as colheitas, em dezembro.

Os princípios ativos utilizados e suas respectivas doses foram os seguintes: benomil $(0,25 \mathrm{~kg} / \mathrm{ha})$; mancozebe $(1,6 \mathrm{~kg} / \mathrm{ha})$; tiofanato metilico $(0,35 \mathrm{~kg} / \mathrm{ha})$; captafol $\left(^{7}\right)(0,78$ litro/ha); clorotalonil $(1,5 \mathrm{~kg} / \mathrm{ha})$; acetato de trifenil estanho $(0,1 \mathrm{~kg} / \mathrm{ha})$;

(7) Captafol: produto atualmente retirado do mercado; carbendazim, tiabendazol e sulfato de cobre - produtos não registrados no Ministério da Agricultura para o feijoeiro. 
carbendazim $(0,3 \mathrm{~kg} / \mathrm{ha})$; tiabendazol $(0,2 \mathrm{litro} / \mathrm{ha})$; oxicloreto de cobre $(0,5 \mathrm{~kg} / \mathrm{ha})$, sulfato de cobre $(0,75 \mathrm{~kg} / \mathrm{ha})$ e hidróxido de trifenil estanho $(0,16 \mathrm{litro} / \mathrm{ha})$.

Efetuaram-se seis pulverizações com intervalo de dez dias, sendo a primeira aos 30 dias após a emergência das plântulas, empregando-se para o controle de pragas, alternadamente, os inseticidas monocrotofos e deltametrina.

Utilizou-se o delineamento experimental de blocos ao acaso, com quatro repetições, sendo cada parcela constituída de quatro linhas de $5 \mathrm{~m}$ de comprimento, espaçadas de $0,5 \mathrm{~m}$, eavaliaram-se as plantas das duas linhas centrais com estande final de dez plantas por metro linear.

Para a avaliação das doenças antracnose, ferrugem, mancha de Alternaria, mancha-angular e bacteriose, empregou-se a seguinte escala de notas de 0 a 5 0 : ausência de sintomas nas plantas; 1 : sintomas em menos de $10 \%$ da área foliar ou superfície da vagem afetada; 2: sintomas em até 25\%; 3: entre 25 e 50\%; 4: entre 50 e 75\%, e 5: acima de 75\%. Foi também avaliada a produção das parcelas.

Para a análise da variância dos resultados, aplicou-se o teste $F$, a $5 \%$ de probabilidade, e para a comparação das médias, o teste de Tukey, também a 5\% de probabilidade.

\section{RESULTADOS E DISCUSSÃO}

$\mathrm{Na}$ safra da seca/85, os fungicidas captafol, clorotalonil, acetato de trifenil estanho e carbendazim proporcionaram as melhores produções do cultivar Carioca: $1.757,5 ; 1.675,0 ; 1.840,0$ e 1.922,5kg/ha respectivamente, e mancozebe, clorotalonil, acetato de trifenil estanho, oxicloreto de cobre e sulfato de cobre, as melhores produções do cultivar Carioca 80 , com 1.681,5; 1.565,0; 1.595,0; 1.580,0 e 1.675,0kg/ha respectivamente (Quadro 1). Nesse ensaio, ocorreu alta incidência de antracnose no 'Carioca' e alta incidência de mancha-angular e mancha de Alternaria em ambos os cultivares (Quadros 2, 4 e 5).

Nas safras das águas/85 e da seca/86, os produtos testados não tiveram efeitos estatisticamente significativos sobre a produção de ambos os cultivares - Quadro 1 - provavelmente porque nas duas safras não tenha ocorrido antracnose. Essa doença foi detectada nas safras da seca/85 e das águas/86 apenas no 'Carioca'. 'Carioca 80' mostrou-se, em todos os ensaios, resistente às raças do fungo causador de antracnose.

No ensaio com o 'Carioca' nas águas/86, os melhores tratamentos foram acetato de trifenil estanho e hidróxido de trifenil estanho, proporcionando produções de 3.652,5 e 3.587,5kg/ha respectivamente, e para o 'Carioca 80 ', o melhor foi o hidróxido de trifenil estanho, com 3.632,5kg/ha (Quadro 1). Nesse ensaio, ocorreu antracnose com uma incidência intermediária no 'Carioca', mancha-angular com baixa incidência no 'Carioca 80', e mancha de Alternaria com incidência alta no 'Carioca 80' (Quadros 2, 4 e 5). 


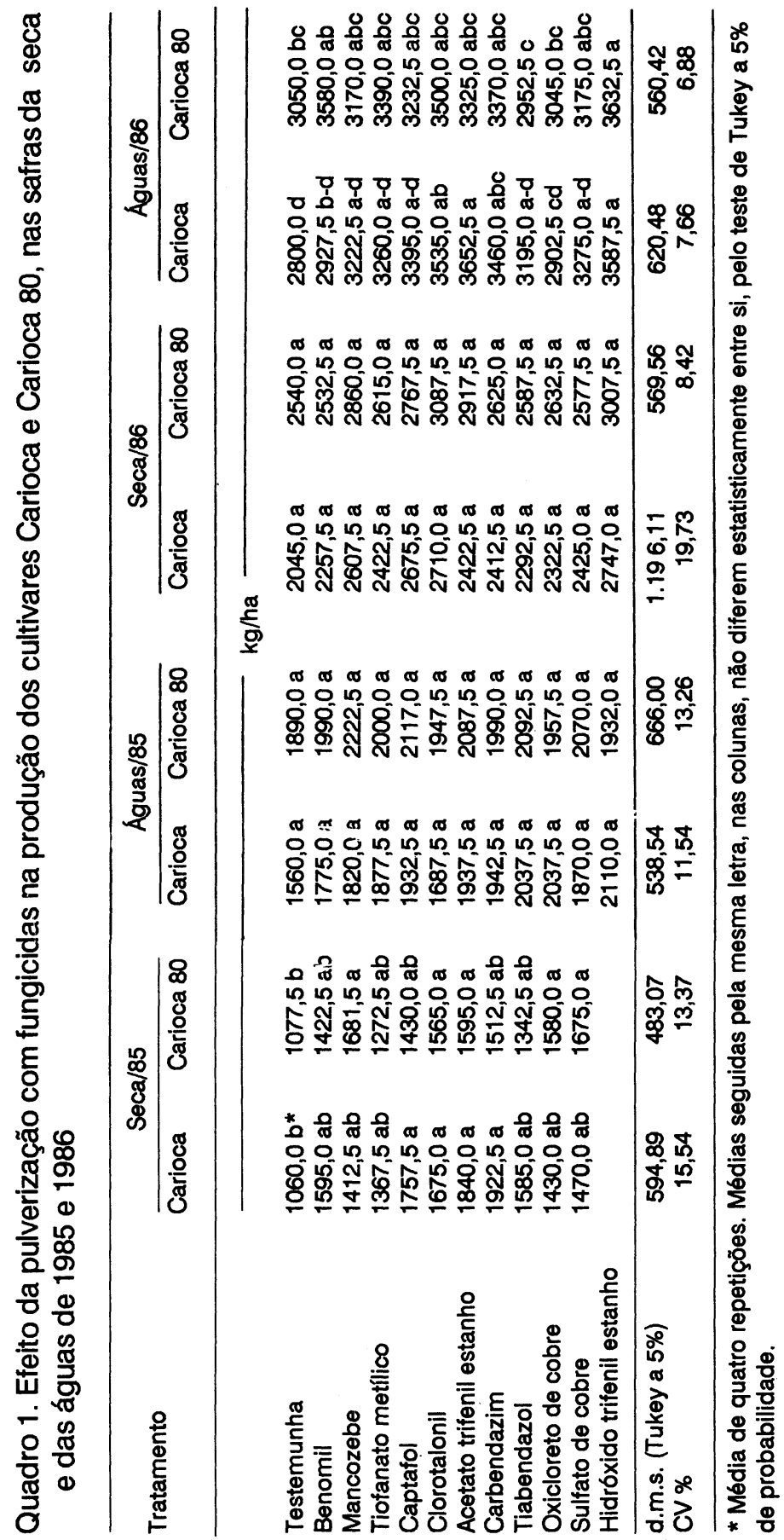


Com relação à antracnose - Quadro 2 - na seca/85, todos os fungicidas a controlaram nas folhas; clorotalonil e acetato de trifenil estanho foram os que mais reduziram sua incidência nas vagens. Nas águas/86 os melhores fungicidas foram mancozebe, captafol, clorotalonil, acetato de trifenil estanho e hidróxido de trifenil estanho, tendo os três últimos reduzido a zero a nota de incidência de doenças (nos últimos três tratamentos referidos). Entre esses, benomil, mancozebe, captafol e clorotalonil são bastante citados na literatura como eficientes para o controle da antracnose (ROLIM et al., 1981; TANAKA \& JUNQUEIRA NETTO, 1982; ISSA et al., 1983; VIEIRA, 1983; SARTORATO, 1985, e CASTRO et al., 1989).

A ferrugem não foi muito importante nos experimentos, em ambos os cultivares, ocorrendo apenas em duas épocas: seca e águas/86 - Quadro 3 - sendo a nota média máxima de infecção 2 (até $25 \%$ de área foliar afetada). $\mathrm{Na}$ seca/86, não houve efeito dos tratamentos no 'Carioca', mas todos os fungicidas foram eficientes no 'Carioca 80'. Nas águas/86, para o 'Carioca', os tratamentos com fungicidas, à exceção do oxicloreto de cobre, diferiram estatisticamente em relação à testemunha. Para o 'Carioca 80', o melhor tratamento foi clorotalonil.

QUADRO 2. Efeito da pulverização de fungicidas na incidência de antracnose no cultivar Carioca (notas de 0 a 5, sendo 0: ausência de sintomas nas plantas, 1: sintomas em menos de $10 \%$ da área foliar ou superfície da vagem afetada; 2: sintomas em até 25\%; 3: entre 25 e $5 n \%$. . . entre 50 e 75\%, e 5: acima de 75\%)

\begin{tabular}{lcccc}
\hline \multirow{2}{*}{ Tratamento } & \multicolumn{2}{c}{ Seca/85 } & Águas/86 \\
\cline { 2 - 3 } & Folhas & Vagens & Folhas e vagens \\
\hline Testemunha & $4,00 \mathrm{~b}^{*}$ & $3,50 \mathrm{e}$ & $2,50 \mathrm{~d}$ \\
Benomil & $0,50 \mathrm{a}$ & $0,63 \mathrm{ab}$ & $0,38 \mathrm{ab}$ \\
Mancozebe & $1,00 \mathrm{a}$ & $0,75 \mathrm{abc}$ & $0,13 \mathrm{a}$ \\
Tiofanato metllico & $1,00 \mathrm{a}$ & $1,00 \mathrm{a}-\mathrm{d}$ & $0,88 \mathrm{abc}$ \\
Captafol & $0,88 \mathrm{a}$ & $1,00 \mathrm{a}-\mathrm{d}$ & $0,13 \mathrm{a}$ \\
Clorotalonil & $0,88 \mathrm{a}$ & $0,50 \mathrm{a}$ & $0,00 \mathrm{a}$ \\
Acetato trifenil estanho & $0,88 \mathrm{a}$ & $0,50 \mathrm{a}$ & $0,00 \mathrm{a}$ \\
Carbendazim & $1,00 \mathrm{a}$ & $1,00 \mathrm{a}-\mathrm{d}$ & $0,88 \mathrm{abc}$ \\
Tiabendazol & $1,00 \mathrm{a}$ & $1,25 \mathrm{bcd}$ & $1,25 \mathrm{bc}$ \\
Oxicloreto de cobre & $1,00 \mathrm{a}$ & $1,38 \mathrm{~cd}$ & $1,50 \mathrm{c}$ \\
Sulfato de cobre & $1,13 \mathrm{a}$ & $1,50 \mathrm{~d}$ & $1,38 \mathrm{c}$ \\
Hidróxido trifenil estanho & - & - & $0,00 \mathrm{a}$ \\
\hline d.m.s. (Tukey 5\%) & 0,64 & 0,63 & 0,89 \\
CV\% & 21,44 & 21,66 & 47,85 \\
\hline
\end{tabular}

* Médias de quatro repetiçőes. Médias seguidas pela mesma letra, nas colunas, não diferem estatisticamente entre si, a $5 \%$ de probabilidade, pelo teste de Tukey. 
QUADRO 3. Efeito da pulverização de fungicidas, na incidência da ferrugem em folhas, nos cultivares Carioca e Carioca 80 (notas de 0 a 5, sendo 0: ausência de sintomas nas plantas; 1: sintomas em menos de $10 \%$ da área foliar ou superfície da vagem afetada; 2: sintomas em até 25\%; 3: entre 25 e $50 \%$; 4: entre 50 e $75 \%$, e 5: acima de $75 \%$ )

\begin{tabular}{lccccc}
\hline \multirow{2}{*}{ Tratamento } & \multicolumn{2}{c}{ Seca/86 } & & \multicolumn{2}{c}{ Aguas/86 } \\
\cline { 2 - 3 } \cline { 6 - 7 } & Carioca & Carioca 80 & & Carioca & Carioca 80 \\
\hline Testemunha & $0,63 \mathrm{a}^{*}$ & $1,00 \mathrm{~b}$ & & $2,00 \mathrm{~b}$ & $1,50 \mathrm{bc}$ \\
Benomil & $0,50 \mathrm{a}$ & $0,63 \mathrm{a}$ & & $1,25 \mathrm{a}$ & $1,13 \mathrm{abc}$ \\
Mancozebe & $0,50 \mathrm{a}$ & $0,50 \mathrm{a}$ & & $1,00 \mathrm{a}$ & $1,00 \mathrm{abc}$ \\
Tiofanato metilico & $0,50 \mathrm{a}$ & $0,63 \mathrm{a}$ & & $1,00 \mathrm{a}$ & $1,25 \mathrm{abc}$ \\
Captafol & $0,50 \mathrm{a}$ & $0,50 \mathrm{a}$ & & $1,00 \mathrm{a}$ & $0,88 \mathrm{abc}$ \\
Clorotalonil & $0,50 \mathrm{a}$ & $0,50 \mathrm{a}$ & & $0,75 \mathrm{a}$ & $0,50 \mathrm{a}$ \\
Acetato trifenil estanho & $0,50 \mathrm{a}$ & $0,50 \mathrm{a}$ & & $1,13 \mathrm{a}$ & $0,63 \mathrm{ab}$ \\
Carbendazim & $0,50 \mathrm{a}$ & $0,50 \mathrm{a}$ & & $1,13 \mathrm{a}$ & $1,00 \mathrm{bc}$ \\
Tiabendazol & $0,50 \mathrm{a}$ & $0,50 \mathrm{a}$ & & $0,75 \mathrm{a}$ & $1,00 \mathrm{abc}$ \\
Oxicloreto de cobre & $0,50 \mathrm{a}$ & $0,50 \mathrm{a}$ & & $1,38 \mathrm{ab}$ & $1,25 \mathrm{abc}$ \\
Sulfato de cobre & $0,50 \mathrm{a}$ & $0,63 \mathrm{a}$ & & $1,13 \mathrm{a}$ & $1,63 \mathrm{c}$ \\
Hidróxido trifenil estanho & $0,50 \mathrm{a}$ & $0,50 \mathrm{a}$ & & $0,75 \mathrm{a}$ & $1,00 \mathrm{abc}$ \\
\hline d.m.s. (Tukey 5\%) & 0,18 & 0,69 & & 0,64 & 0,88 \\
CV\% & 14,14 & 26,43 & & 23,32 & 33,36 \\
\hline
\end{tabular}

* Média de quatro repetições. Médias seguidas pela mesma letra, nas colunas, não diferem estatisticamente entre si a $5 \%$ de probabilidade, pelo teste de Tukey.

$O$ produto que apresentou algum controle de ferrugem foi o clorotalonil, 0 que concorda com resultados de CASTRO et al. (1989). Alguns trabalhos mostraram a eficiência de fungicidas mais especfficos, como carboxim ou oxicarboxim (ZAMBOLIM \& CHAVES, 1978); bitertanol (SANTINI, 1989); diniconazole (MANÇO, 1988) e etiltrianol (GOULART, 1989, e SANTINI, 1989).

A mancha-angular foi a doença de maior freqüência e severidade nas safras avaliadas, não ocorrendo apenas na das águas/85 - Quadro 4. Na da seca/85, alcançou-se o melhor controle da doença, tanto em folhas como em vagens, com mancozebe, clorotalonil e acetato de trifenil estanho. Na seca/86, no 'Carioca', o hidróxido de trifenil estanho foi o mais eficiente para o controle da mancha-angular em folhas, enquanto em vagens se destacaram mancozebe, captafol, clorotalonil, acetato de trifenil estanho e hidróxido de trifenil estanho. Nessa safra, em folhas do 'Carioca 80', exceto o sulfato de cobre, todos os fungicidas foram eficientes em vagens, sobressaindo clorotalonil, acetato de trifenil estanho e hidróxido de trifenil estanho. Nas safras das águas/86, para ambos os cultivares, em folhas, destacaram-se clorotalonil, acetato de trifenil estanho e hidróxido de trifenil estanho, e para o 'Carioca', em vagens, além desses, 0 ' ancozeb. Para o 'Carioca 80', em vagens, o hidróxido de trifenil estanho foi o mais eficiente. 


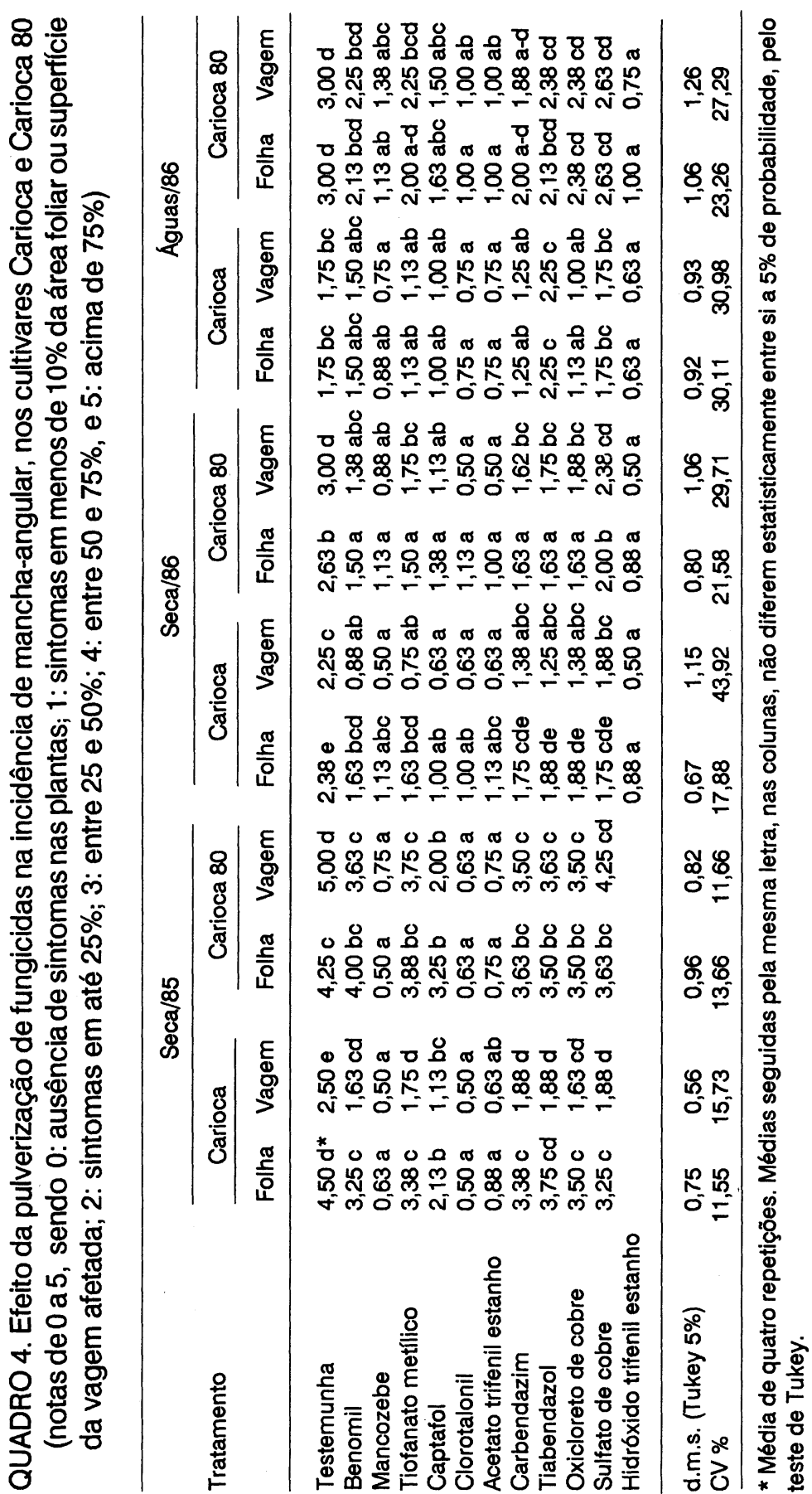


Por esses resultados, conclui-se que os melhores fungicidas para controle da mancha-angular foram: mancozebe, clorotalonil, acetato de trifenil estanho e hidróxido de trifenil estanho. Clorotalonil e mancozebe vêm sendo recomendados por diversos autores.

A mancha de Alternaria também foi de ocorrência generalizada em todos os ensaios - Quadro 5. Nas safras da seca e das águas/85, foi observada apenas em folhas dos dois cultivares. Na seca/85, para o 'Carioca', os fungicidas mais eficientes foram captafol e clorotalonil,e para o 'Carioca 80', além desses dois, mancozebe e acetato de trifenil estanho. Nas águas/85, para o 'Carioca', os melhores fungicidas foram acetato de trifenil estanho e hidróxido de trifenil estanho,e para o 'Carioca 80 ', hidróxido de trifenil estanho. Na safra da seca/86, essa doença ocorreu apenas em folhas do 'Carioca' e em folhas e vagens do 'Carioca 80'. Os melhores fungicidas para sua redução no 'Carioca' foram mancozebe, captafol, clorotalonil, acetato de trifenil estanho e hidróxido de trifenil estanho. Clorotalonil, acetato de trifenil estanho e hidróxido de trifenil estanho foram os mais eficazes para folhas no 'Carioca' 80 '; para vagens, além desses três, destacou-se o mancozebe. Na safra das águas/86, a mancha de Alternaria ocorreu em folhas e vagens dos dois cultivares. O tratamento com clorotalonil, nesse último ensaio, destacou-se no controle da doença em folhas de ambos e em vagens do 'Carioca 80'. Para o controle em vagens do 'Carioca', os melhores tratamentos foram captafol e hidróxido de trifenil estanho.

De maneira geral, para o controle de mancha de Alternaria, destacaram-se os mesmos fungicidas eficientes para o controle da mancha-angular. Nesses ensaios, os fungicidas mais eficazes reduziram as notas de infecção para valores menores que 1 (menos de $10 \%$ de área foliar ou vagens afetadas). Clorotalonil e mancozebe já se haviam mostrado eficientes para o controle de mancha de Alternaria (CASTRO et al., 1989).

O crestamento bacteriano também ocorreu de forma generalizada, com baixa incidência, não afetando as vagens dos dois cultivares testados - Quadro 6. $\mathrm{Na}$ seca/85, ocorreu apenas no 'Carioca', mostrando mancozebe algum controle da doença. Na safra das águas/85, a pulverização com acetato de trifenil estanho proporcionou uma redução da doença em ambos os cultivares. $\mathrm{Na}$ seca/86, apesar da baixa incidência da doença, os melhores tratamentos para 'Carioca' e 'Carioca 80 ' foram clorotalonil, acetato de trifenil estanho e hidróxido de trifenil estanho, e para o 'Carioca 80', além desses três, o mancozebe. Nas águas/86, para ambos, mancozebe, tiofanato metllico, clorotalonil, acetato de trifenil estanho e hidróxido de trifenil estanho diferiram estatisticamente da testemunha. Benomil e captafol também reduziram a incidência da doença no cultivar Carioca.

Para controle do crestamento bacteriano, portanto, destacaram-se mancozebe, clorotalonil, acetato de trifenil estanho e hidróxido de trifenil estanho, que se haviam mostrado também os mais eficientes no controle da mancha-angular e mancha de Alternaria. Outros autores têm recomendado, para o controle do crestamento comum, fungicidas como oxicloreto de cobre em mistura com zinebe ou mancozebe (KIMATI et al., 1986, e MARINGONI, 1988). 


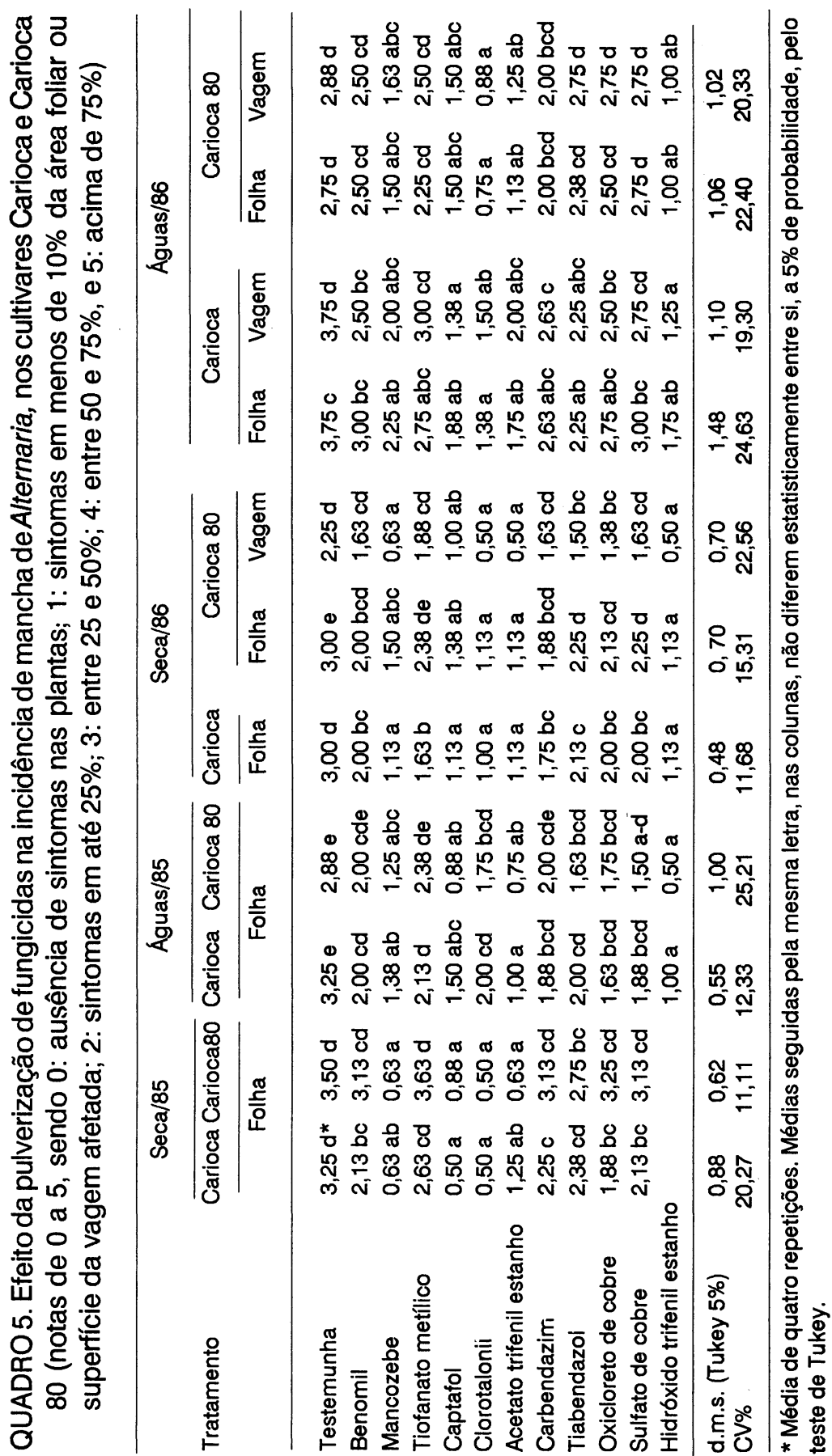




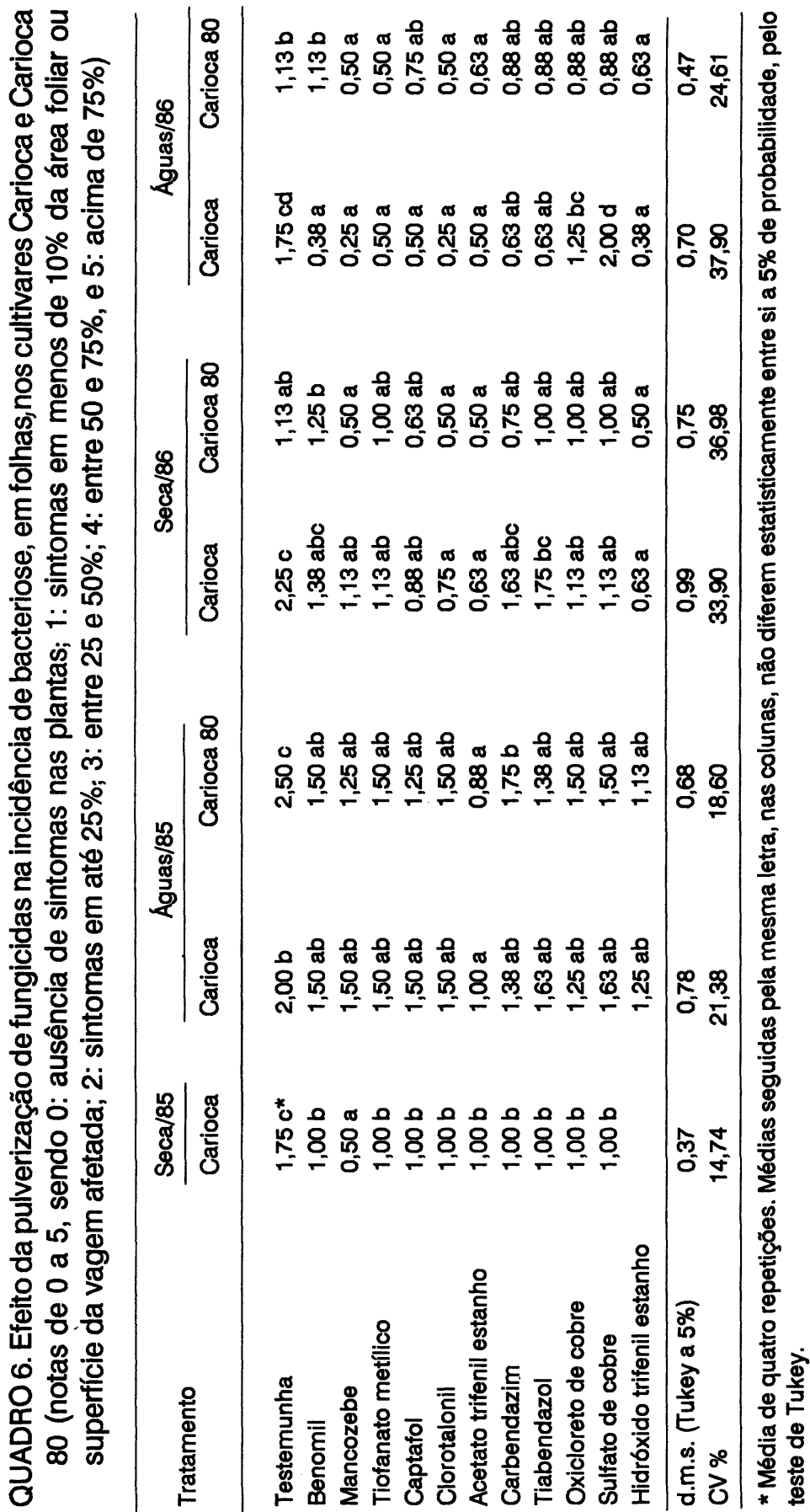




\section{REFERÊNCIAS BIBLIOGRAFICAS}

ANUÁRIO ESTATÍSTICO DO BRASIL. Rio de Janeiro, IBGE, v.50, 1990.

CASTRO, J.L.; DUDIENAS, C.; ITO, M.F. \& IGUE, T. Eficiência de fungicidas no controle das doenças do feijoeiro (Phaseolus vulgaris L.). Summa Phytopathologica, Jaguariúna, 15(2):145-155, 1989.

GOULART, A.C.P. Eficiência de fungicidas no controle de doenças foliares do feijoeiro (Phaseolus vulgaris L.). Summa Phytopathologica, Jaguariúna, 15(1):8, 1989. (Resumo)

ISSA, E. Estudo comparativo de aplicaçöes de fungicidas, isoladamente em alternâncias e em misturas, para controle de doenças das vagens do feijoeiro, Phaseolus vulgaris L. O Biológico, São Paulo, 51 (6):141-146, 1985.

-; SINIGAGLIA, C. \& OLIVEIRA, D.A. Controle químico da antracnose (Colletotrichum lindemuthianum (Sacc. \& Magn.) Scrib.) e de duas outras doenças do feijoeiro (Phaseolus vulgaris L.). O Blológico, São Paulo, 49(4):89-95, 1983.

KIMATI, H.; SOAVE, J.; ESKES, A.B.; KUROZAWA, C.; BRIGNANI NETO, F. \& FERNANDES, N.G. Gula de fungicidas agrícolas. Piracicaba, Livroceres, 1986. 281p.

MAFFIA, L.A.; CARMO, M.G.F. \& KATSURAYAMA, Y. Epidemiologia e controle de principais doenças do feijoeiro. In: SEMINÁRIO SOBRE PRAGAS E DOENÇAS DO FEIJOEIRO, 3., Piracicaba, 1988. Anais. Piracicaba, 1988. p.103-126.

MANÇO, G.R. Diniconazole, um fungicida contra ferrugens. Fitopatologia Brasileira, Brasília, 13(2):142, 1988. (Resumo)

MARINGONI, A.C. Efeito de produtos químicos no controle do crestamento bacteriano comum do feijoeiro, e na transmissibilidade da Xanthomonas campestris pv. phaseoli na semente. Fitopatologia Brasileira, Brasília, 13(2):97, 1988. (Resumo)

RODRIGUES, C.H.; ZAMBOLIM, L. \& MARTINS, M.C.P. Eficiência de fungicidas no controle da mancha-angular (lsariopsis griseola) do feijoeiro (Phaseolus vulgaris). Fitopatologia Brasileira, Brasília, 12(1):40-45, 1987.

ROLIM, P.R.R.; BRIGNANI NETO, F.; ROSTON, A.J. \& OLIVEIRA, D.A. Controle químico das doenças do feijoeiro (Phaseolus vulgaris L.): Ill. Controle da antracnose em feijäo das águas. O Biológico, São Paulo, 47(9):245-248, 1981.

— ; _ - \& \& - Emprego de fungicidas na cultura do feijão. In: SEMINÁRIO SOBRE PRAGAS E DOENÇAS DO FEIJOEIRO, 1., 2., Campinas, 1980, 1985. Resumos. Campinas, Instituto Agronômico, 1985. p.21.

SANTINI, A. Estudo do efeito de fungicidas no controle da ferrugem do feijão (Uromyces phaseoll var. typica Arth.). Fitopatologia Brasileira, Brasília, 14(2):145, 1989. (Resumo)

SARTORATO, A. Feijāo: doenças causadas por fungos. Informe Agropecuário, Belo Horizonte, 11 (131):76-77, 1985.

SGARBIERI, V.C. Composição e valor nutritivo do feijão (Phaseolus vulgaris L.). In: BULISANI, E., coord. Feijão: fatores de produção e qualidade. Campinas, Fundação Cargill, 1987. cap. 5, p.257-326. 
TANAKA, M.A.S. \& JUNQUEIRA NETTO, A. Efeito de fungicidas sistêmicos sobre a intensidade de doenças na parte aérea e a qualidade sanitária da semente de feijão (Phaseolus vulgaris $L$.). Fitopatologia Brasileira, Brasília 7(3):381-386, 1982.

VIEIRA, C. Doenças e pragas do feijoeiro. Viçosa, Imprensa Universitária - UFV, 1983. 231p.

ZAMBOLIM, L. \& CHAVES, G.M. Doenças do feijoeiro e seu controle. Informe Agropecuário, Belo Horizonte, 4(46):49-63, 1978. 